\title{
Factors associated with pediculosis pubis and scabies
}

Gavin Hart

\begin{abstract}
Objective-To ascertain factors associated with genital pediculosis and scabies infestations among attenders at an STD clinic.

Design-Cross sectional assessment of potential risk factors by multiple logistic regression.

Setting-A central city sexually transmitted diseases (STD) clinic in Adelaide, South Australia.

Subjects-All men and women patients attending from 1988 to 1991.

Results-Pediculosis pubis was diagnosed in 205 of $12170(1 \cdot 7 \%)$ men and $65(1 \cdot 1 \%)$ of 6125 women, and scabies in $56(0.5 \%)$ men and $6(0 \cdot 1 \%)$ women attending an STD clinic from 1988-1991. Independent risk factors by multivariate analysis for pediculosis pubis in women were pregnancy (odds ratio $(O R)=2 \cdot 3$ ), sex outside the state $(O R=2 \cdot 2)$ and age under 25 $(O R=2 \cdot 0)$. Many factors were associated with pediculosis pubis in men, including no steady partner $(O R=1.4)$, multiple partners $(O R=1 \cdot 6)$, being unmarried $(O R=2 \cdot 0)$ and homosexual behaviour $(O R=1 \cdot 6)$. None of these factors was associated with scabies infestation which was strongly associated with being Aboriginal $(O R=6.8)$ and being unemployed $(\mathrm{OR}=2 \cdot 5)$.

Conclusion-In this setting scabies appears to be determined by socioeconomic factors and pediculosis pubis predominantly by sexual activity factors.
\end{abstract}

\section{Introduction}

Although epidemics of scabies and human lice have been observed for centuries very little has been recorded about the epidemiology of the sexually transmitted forms of these diseases ${ }^{12}$ which are seen commonly in sexually transmitted disease clinics. In the present study, attenders at a sexually transmitted disease (STD) clinic from 1988-1991 were examined for scabies and pediculosis pubis and a wide range of independent variables analysed by multiple logistic regression to define independent correlates of infestation.

STD Control Branch, Box 65, Rundle Mall PO, South Australia 5000.

Gavin Hart

Accepted for publication 24 April 1992 (including the variables listed in the table) for all STDs, patients were examined to detect evidence of infestation. Pediculosis was
Following standardised risk assessment diagnosed by observation of pubic lice or their eggs attached to pubic hairs, scabies by observation of typical lesions in association with supportive history (such as nocturnal itching, exposure to infestation). Where possible diagnoses of scabies were confirmed by microscopic demonstration of the mite, but over $50 \%$ of diagnoses were made on clinical grounds. Clinical diagnoses were confirmed by full time specialist clinicians.

Factors associated with infestation were detected by means of multiple logistic regression using SPSS/PC ${ }^{+}$V3.1. ${ }^{3}$ The dichotomous independent variables compared patients with the specific infestation with those not affected. The dichotomous independent variables were those found to be associated with one or more STD in this clinic (table). Univariate analysis was performed using Epi Info. ${ }^{4}$ Confidence limits $(95 \%)$ for odds ratios were calculated using Cornfield's approximation. ${ }^{5}$ Confidence limits for the Mantel Haenszel weighted odds ratio $^{6}$ (summary odds ratio) were calculated using the formulas of Robins, Greenland and Breslow. ${ }^{7}$ Because of the small number of scabies infestations in women, risk factors were not analysed for this group.

\section{Results}

Pediculosis pubis was diagnosed in $205(1.7 \%)$ of 12170 men and $65(1.1 \%)$ of 6125 women, and scabies in $56(0.5 \%)$ men and $6(0.1 \%)$ women. Of these men $6029(50 \%)$ had no illness, 4307 (35\%) had one or more STDs (as defined in the table) and $1834(15 \%)$ had only non-STD illness, and 3273 (53\%) women had no illness, $1856(30 \%)$ had one or more STDs and $996(16 \%)$ had only non-STD illness. The factors independently associated (by multiple logistic regression) with infestation are shown in the table. Of the $\mathbf{4 3 1}$ women in this study who were pregnant $308(71 \%)$ were never married, $80(19 \%)$ were married and $43(10 \%)$ were formerly married. There was no significant difference in marital status of those with pediculosis and those not having pediculosis $(p=0.57)$. Univariate analysis showed a positive association between scabies and tattoos $(\mathrm{OR}=2 \cdot 2(1 \cdot 2-4 \cdot 1))$ due to confounding with being unemployed and being Aboriginal (summary $O R=1.5(0.8-2.8)$ ), and with IV drug use $(O R=2 \cdot 4(1 \cdot 2-4 \cdot 9))$ due to confounding with the same factors (summary OR $=1 \cdot 7(0 \cdot 8-3 \cdot 4)$ ).

Similarly positive associations of IV drug use with pediculosis in men (OR $=1.8(1 \cdot 2-2 \cdot 7)$ by univariate analysis) was due to confounding 
Table Factors associated with pediculosis pubis in men and women and scabies in men, 1988-1991. All odds ratios from multiple logistic regression

\begin{tabular}{|c|c|c|c|c|c|c|}
\hline \multirow[b]{3}{*}{ Factor * } & \multicolumn{4}{|l|}{ Pediculosis } & \multirow{2}{*}{\multicolumn{2}{|c|}{$\frac{\text { Scabies }}{\text { Men }}$}} \\
\hline & \multicolumn{2}{|l|}{ Women } & \multicolumn{2}{|l|}{ Men } & & \\
\hline & $\begin{array}{l}\text { Odds ratio } \\
\text { ( } p \text { value) }\end{array}$ & $\begin{array}{l}\% \text { of } \\
\text { positives }\end{array}$ & $\begin{array}{l}\text { Odds ratio } \\
\text { ( } p \text { value })\end{array}$ & $\begin{array}{l}\% \text { of } \\
\text { positives }\end{array}$ & $\begin{array}{l}\text { Odds ratio } \\
\text { ( } p \text { value) }\end{array}$ & $\begin{array}{l}\text { \% of } \\
\text { positives }\end{array}$ \\
\hline Pregnant & $2.3(0.03)$ & 15 & - & - & - & - \\
\hline Age under 25 & $2.0(0.03)$ & 69 & $1.6(0.001)$ & 50 & $\|$ & 38 \\
\hline Sex outside state† & $2.2(0.02)$ & 20 & $\|$ & 14 & II & 18 \\
\hline $\begin{array}{l}\text { Genital } \\
\text { Discharge/Dysuria }\end{array}$ & $\|$ & 23 & $0 \cdot 3^{\star \star}$ & 8 & $0.4(0.09)$ & 7 \\
\hline Other STD $\ddagger$ & $\|$ & 37 & $0.6(0.004)$ & 16 & $0.5(0.07)$ & 16 \\
\hline STD contact & $\|$ & 15 & $0.3(0.0006)$ & 4 & $0.2(0.07)$ & 2 \\
\hline No steady partnert & $\|$ & 51 & $1.4(0.04)$ & 67 & $\|$ & 64 \\
\hline Multiple partnerst & $\|$ & 36 & $2.6(0.0003)$ & 60 & $\|$ & 37 \\
\hline Unmarried & $\|$ & 90 & $2.0(0.02)$ & 93 & $\|$ & 88 \\
\hline Tattoos & $\|$ & 14 & $1.5(0.03)$ & 21 & \|I & 27 \\
\hline Uncircumcised & - & - & $1.5(0.007)$ & 48 & $\|$ & 36 \\
\hline Homosexual & - & - & $1.6(0.01)$ & 21 & $\|$ & 18 \\
\hline Unemployed & $\|$ & 20 & $1.4(0.06)$ & 30 & $2.5(0.001)$ & 45 \\
\hline Aboriginal & $\|$ & 0 & $\|$ & 1 & $6.8(0.0001)$ & 9 \\
\hline
\end{tabular}

*Being a prostitute, oral contraception, parity and gravidity were not associated with pediculosis in women; and past STD, IV drug use, being Asian or having gonorrhoea or chlamydia were not associated with any of the infestations in men or women.

In the past 3 months.

†Includes gonorrhoea, syphilis, herpes, chlamydia, warts, trichomoniasis, bacterial vaginosis, molluscum contagiosum.

molluscum contagiosum.

i $>0 \cdot 10$

$\mid \mathrm{p}>0.10$
$\star{ }^{*} \mathrm{p}<0.0001$ factors, including several which are characteristic of STDs (viz no steady partner $(O R=1 \cdot 4)$, multiple partners $(O R=2 \cdot 6)$, age under 25 years $(\mathrm{OR}=1 \cdot 6)$, being unmarried $(\mathrm{OR}=2 \cdot 0)$, homosexual behaviour $(\mathrm{OR}=$ $1 \cdot 6)$ ). Although scabies and pediculosis in men were both inversely associated with being an STD contact, and with other STDs collectively, the former, alone, was strongly associated with being Aboriginal $(O R=6.8)$ and being unemployed $(\mathrm{OR}=2 \cdot 5)$, and not associated with the factors more directly related to sexual behaviour.

Although pediculosis in men was associated with numerous markers of sexual activity (for example multiple partners and homosexual behaviour) it was inversely associated with having other STD. This reflects the subtleties of STD epidemiology whereby apparently similar diseases have quite marked differences in some facets of their epidemiology. Thus it is well documented ${ }^{10}$ that in men gonorrhoea is directly associated with and chlamydia inversely associated with homosexual behaviour. Gonorrhoea and chlamydia are directly associated with having multiple sex partners for men but not for women. ${ }^{10} 11$ Perhaps differences in transmission rates and mechanisms contribute to disparities in these relationships, and transmission by body contact in the absence of intromission could be a factor.

In this setting, scabies appears to be determined predominantly by socioeconomic factors and pediculosis predominantly by sexual activity factors. These differences are of prime importance in planning strategies to reduce the frequency of these diseases.

This study confirms the suggestion that pediculosis pubis is more common in unmarried persons under age $25,{ }^{2}$ but is in direct opposition to the observation of higher prevalence of scabies among whites than among non-whites ${ }^{8}$ and a direct relationship with gonorrhoea. ${ }^{9}$

The epidemiology defined by multivariate analysis is quite distinctive. Pediculosis pubis in women was independently associated with only three of the factors studied (pregnancy $(O R=2 \cdot 3)$, sex outside the state $(O R=2 \cdot 2)$ and age under 25 years $(O R=2 \cdot 0)$. The dominance of unmarried women $(81 \%)$ among those pregnant shows that the study sample was not typical of the general population in this regard, and the independent association of pregnancy and pediculosis may not occur in the wider community. Pregnancy (which is presumably unwanted in many of these unmarried women) is probably a marker of some facet of sexual behaviour which was not measured by the other independent variables (such as multiple partners or no steady partner) used in the model.

Pediculosis in men was associated with many
1 Maibach H. Holmes KK, Sparling PF, Weisher PJ, eds Scabies in Sexually Transmitted Diseases, New York, McGraw Hill, 2nd ed, 1990. Transmitted Diseases, New York, McGraw Hill, 2nd ed, 1990.

3 SPSS $/$ C C $^{+}$(computer program) Version 3.1. Chicago: SPSS Inc., 1989.

4 Dean AG, Dean JA, Burton AH, Dicker RC. Epi Info, version 5: a word processing, database and statistics program for epidemiology on microcomputers. Stone Mountain, Georfor epidemiology on microcon

5 Fleiss JL. Statistical Methods for Rates and Proportions, New York: John Wiley and Sons, 1981;71-5.

6 Mantel N, Haenszel W. Statistical aspects of the analysis of data from retrospective studies of disease. $\mathcal{F}$ Natl Cancer Inst 1959;22:719-48.

7 Robins J, Greenland S, Breslow NE. A general estimator for the variance of the Mantel-Haenszel odds ratio. $\mathrm{Am} \mathrm{f}$ Epidemiol 1986;124:719-23.

8 Alexander AM. Role of race in scabies infestation. Arch Dermatol 1978;114:627.

9 Nielsen AO, Secher L, Seier K. Gonorrhoea in patients with scabies. Br $\mathcal{F}$ Venereal Dis 1976;52:394-5.

10 Hart G. Factors associated with genital chlamydial and gonococcal infection in males. Genitourin Med (in

11 Hart $G$. Factors associated with genital chlamydial and gonococcal infection in females. Genitourin Med (in press).
2 Billstein SA. Holmes KK, et al eds. Human lice in Sexually 